\title{
Heat transfer research on enhanced heating surfaces in pool boiling
}

\author{
Wojciech Kalawa ${ }^{l, *}$, Tadeusz M. Wójcik ${ }^{l}$, Magdalena Piasecka $^{2}$ \\ ${ }^{1}$ AGH University of Science and Technology, al A. Mickiewicza 30 , 30-059 Krakow, Poland \\ ${ }^{2}$ Kielce University of Technology, Al. 1000-lecia P.P. 7, 25-314 Kielce, Poland
}

\begin{abstract}
The paper focuses on the analysis of the enhanced surfaces in such applications as boiling heat transfer. The testing measurement module with enhanced heating surfaces was used for pool boiling research. Pool boiling experiments were conducted with distilled water at atmospheric pressure in the vessel using an enhanced sample as the bottom heating surface. The samples are soldered to a copper heating block of the round cross-section . They were placed: in the fluid (saturation temperature measurement), under the sample for temperature determination. A vessel made of four flat glass panes was used for visualization. The heated surfaces in contact with the fluid differed in roughness were smooth or enhanced. This paper analyzes the effects of the microstructured heated surface on the heat transfer coefficient. The results are presented as relationships between the heat transfer coefficient and the heat flux and as boiling curves. The experimental data obtained for the two types of enhanced heated surfaces was compared with the results recorded for the smooth heated surface. The highest local values of the heat transfer coefficient were reported for the enhanced surfaces.
\end{abstract}

\section{Introduction}

With the ever-evolving state of the technology it is observed an increase in the intensity of heat flux in electronic systems and other modern technologies: military, space and medical. In addition, more and more often the focus is on minimizing the size of the heat exchangers, while maximizing leads heat flux. Therefore, there is a need to conduct research in the field of intensification of heat transfer.

One of the ways of intensification of heat transfer is the use of boiling phenomena, that is a phase change of the working fluid. Boiling is a process in which, due to bring heat to the liquid, the liquid inside the vapour phase formation of a liquid phase.

The boiling process is considered with regard to the classification of flow boiling, for which the geometry of space and hydrodynamics of the flow have a significant impact on the mechanisms of heat transfer and boiling in volume, for which these parameters have no effect on the course of the process. A special type of boiling is boiling in large volume - pool boiling. Such a process occurs, when due to the a much smaller size of the boundary layer in comparison with the dimension of the tank, there is no impact of the geometry of the tank on the boiling.

The development of technology, including electronics, requires providing huge heat fluxes, that boiling on the technically smooth surface becomes insufficient.

Among the methods of intensification of boiling are: active methods, requiring an additional supply of substances or energy into the liquid - heated surface, passive methods - without bringing the energy, involving the selection of the heat transfer surface or liquid, and complex methods, which are a combination of the listed above two methods. In recent years, mainly passive methods are being developed, both in the application of porous coatings (including thermal spraying methods, sintering of powders or fibers) and due to mechanical processing of the metal surface. The last of these methods involves changing of the shape of the heat transfer surface by producing e.g. holes, ribs or by increasing roughness of the surface. The extensive research on the passive methods shows that modifying the characteristics and structure of the heat transfer surface results in higher energy-efficiency and material saving.

In order to intensify boiling heat transfer tends to enlarge the heated surface, increasing the number of active nucleation centers, to ensure continuous operation and the activation at lower superheating of the heated surface in comparison to a smooth surface. Properly selected structure on the heated surface allows to significant increase in the heat transfer coefficient in comparison with obtained for the technically smooth surface.

Pool boiling process on the microstructured surface differs in comparison to the process taking place on the technically smooth surface. The values of the heat transfer coefficient differ strongly depends on the material characteristics of a porous layer. 
In Figure 1 the results of experimental research on pool boiling heat transfer on microstructured surfaces laboratory-produced both in industry and commerce is shown. Results are presented as boiling curves (heat flux $q$ versus surface superheating $\Delta T$ ) for water with heat flux increasing, for selected surfaces.

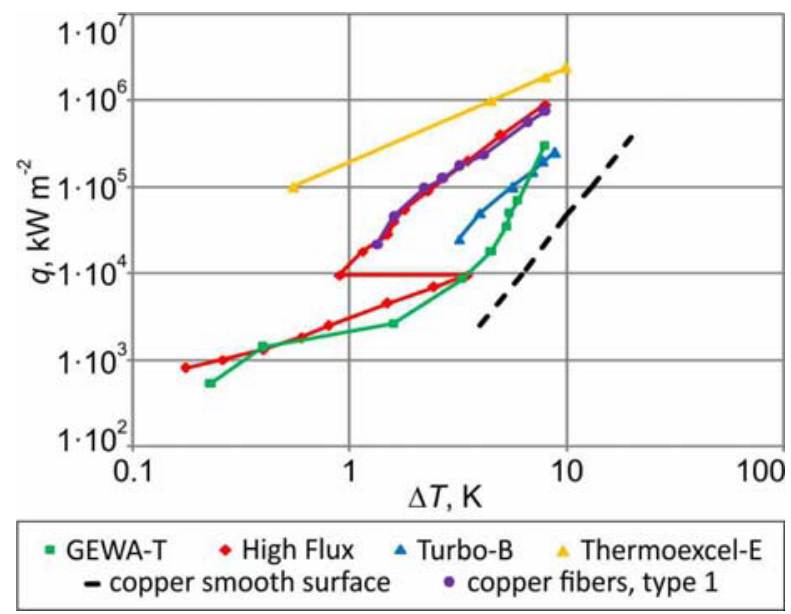

Fig. 1. Test results of experimental research on pool boiling heat transfer on microstructured surfaces [8].

Water has been chosen as a working fluid in the study, based on the literature review as an extensive database of experimental results can be found. Timeliness of the issue and the variety of available research results of own data and described in the literature allow to analyze the boiling process on different surfaces.

The analysis of experimental studies resulting from the author's experience in a flow boiling heat transfer in minichannels [1-3] indicates that lower heat flux was supplied using enhanced heated surfaces compared to the smooth surface. Values of the local heat transfer coefficient have proved higher when results from the enhanced heating surfaces were noticed [2-4]. Enhanced heating surfaces were produced using various techniques, e.g. laser texturing and modified spark erosion. Some research have been undertaken to produce porous coatings to be deposited on heating surfaces using an innovative technology which are mainly used in pool boiling research $[1,5,11]$. It involves sintering metallic powder in the dissociated ammonia atmosphere to generate diffusion-origin pores $[6,7]$.

\section{Research methodology}

\subsection{Object of study}

In the current study, the tested porous surfaces were produced by sintering iron powder (Fe) of ASC100.29 with the stainless steel plate in the dissociated ammonia atmosphere and by soldering iron powder or stainless steel fibers to the stainless steel plate. Soldering was carried out in according to the patent application [8]: once the surface was covered with a thin film of solder and flux, the fragmented structures of metallic material (powders, fibres) were joined by soldering to the plate.
Figures 2 - 6 show 3D topographies and roughness profiles for five types of porous surfaces used in a pool boiling research. One of them (powder, type 1) was produced by sintering unsorted iron powder (size of the granulate $45 \div 250 \mu \mathrm{m}$ ) with the stainless steel plate in the dissociated ammonia atmosphere (Fig. 2). Next two types were produced by soldering sorted iron powders: of size of the granulate below $80 \mu \mathrm{m}$ (powder, type 2, Fig. 3) and of size of the granulate above $95 \mu \mathrm{m}$ (powder, type 3, Fig. 4), to the stainless steel plate.
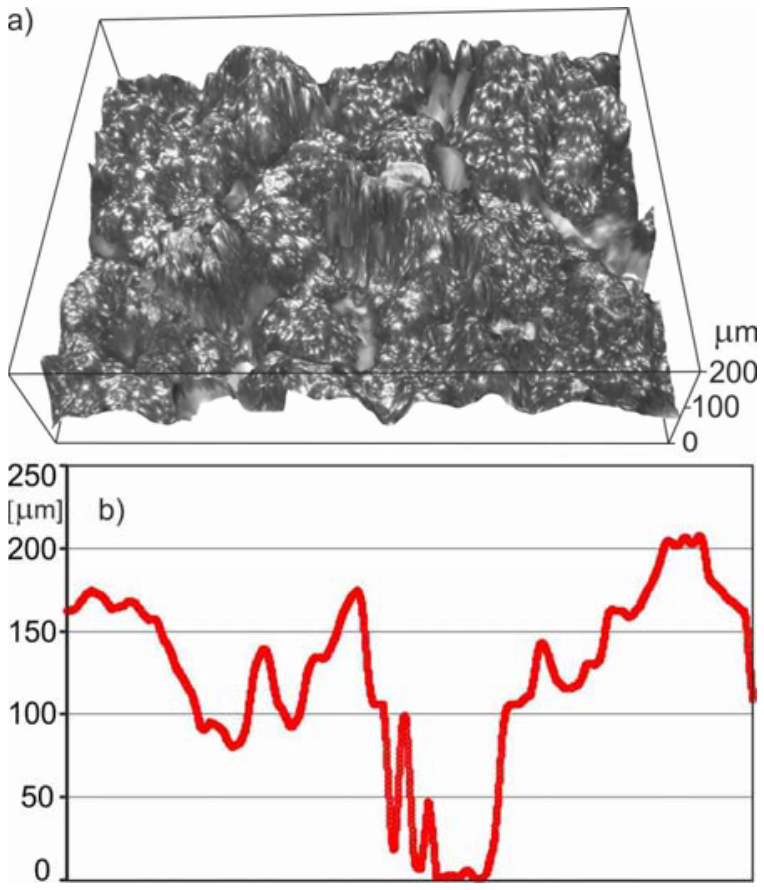

Fig. 2. Porous surface produced by sintering iron powder, type 1 (unsorted, size of the granulate $45 \div 250 \mu \mathrm{m}$ ): a) $3 \mathrm{D}$ topography, b) roughness profile.

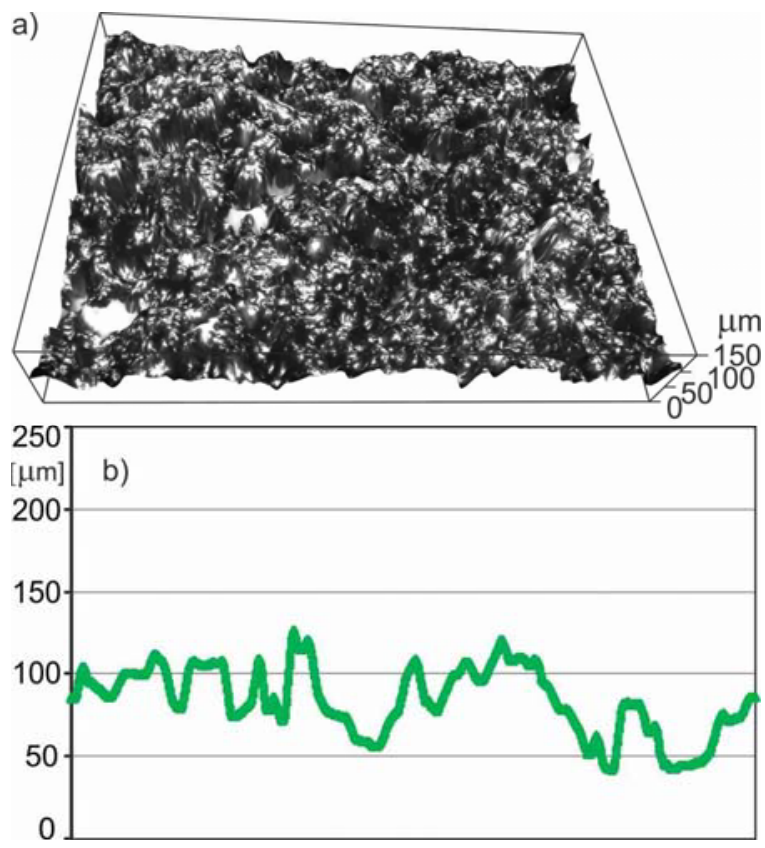

Fig. 3. Porous surface produced by soldering iron powder, type 2 (sorted, size of the granulate below $80 \mu \mathrm{m}$ ): a) $3 \mathrm{D}$ topography, $\mathrm{b}$ ) roughness profile. 
The last two types of porous surfaces were produced by soldering stainless steel fibres of different average fibre diameters: of $10 \mu \mathrm{m}$ (fibre, type 1, Fig. 5) and of $25 \mu \mathrm{m}$ (fibre, type 2, Fig. 6) to the stainless steel plate.
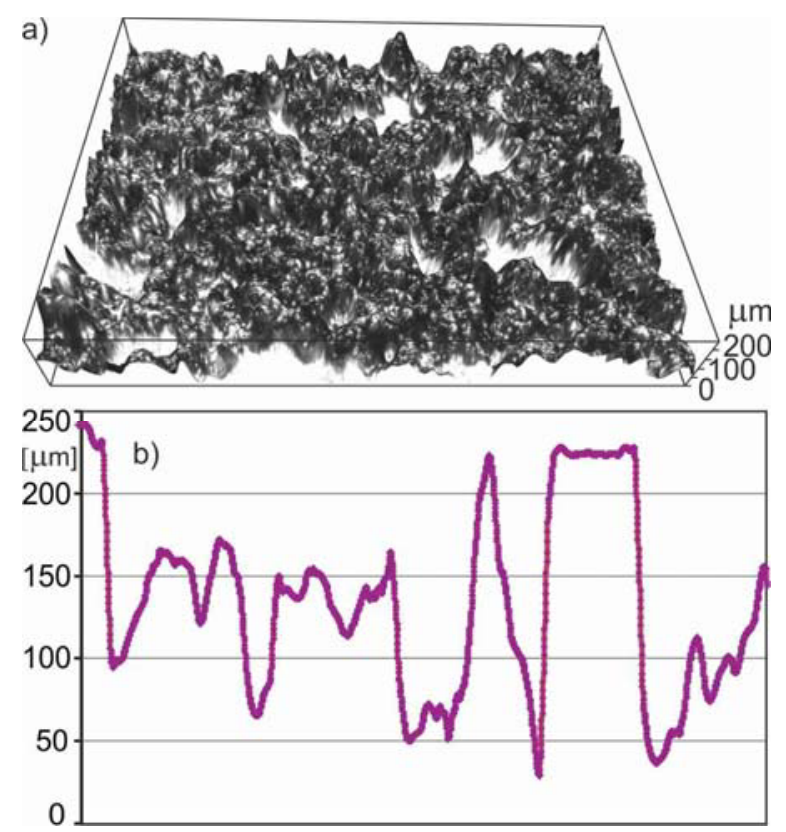

Fig. 4. Porous surface produced by soldering iron powder, type 3 (sorted, size of the granulate above $95 \mu \mathrm{m}$ ):

a) $3 \mathrm{D}$ topography, b) roughness profile.
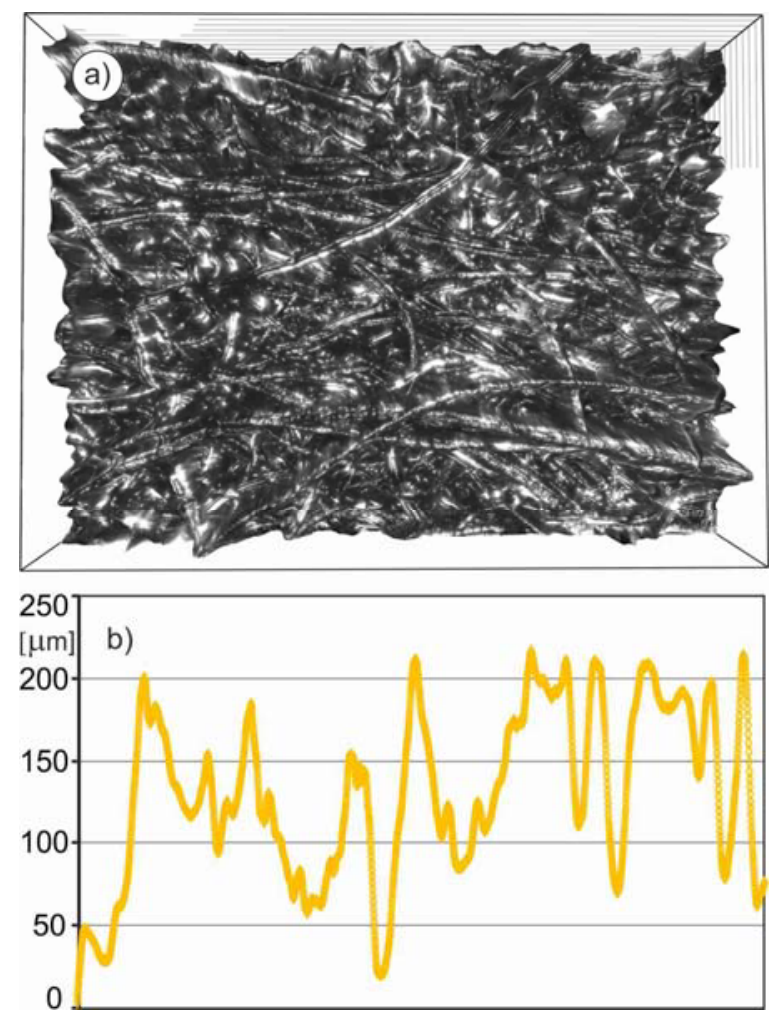

Fig. 5. Plate surface enhanced by soldering stainless steel fibres, type 1 (average fibre diameter - $10 \mu \mathrm{m}$ ):

a) $3 \mathrm{D}$ topography, $\mathrm{b}$ ) roughness profile.
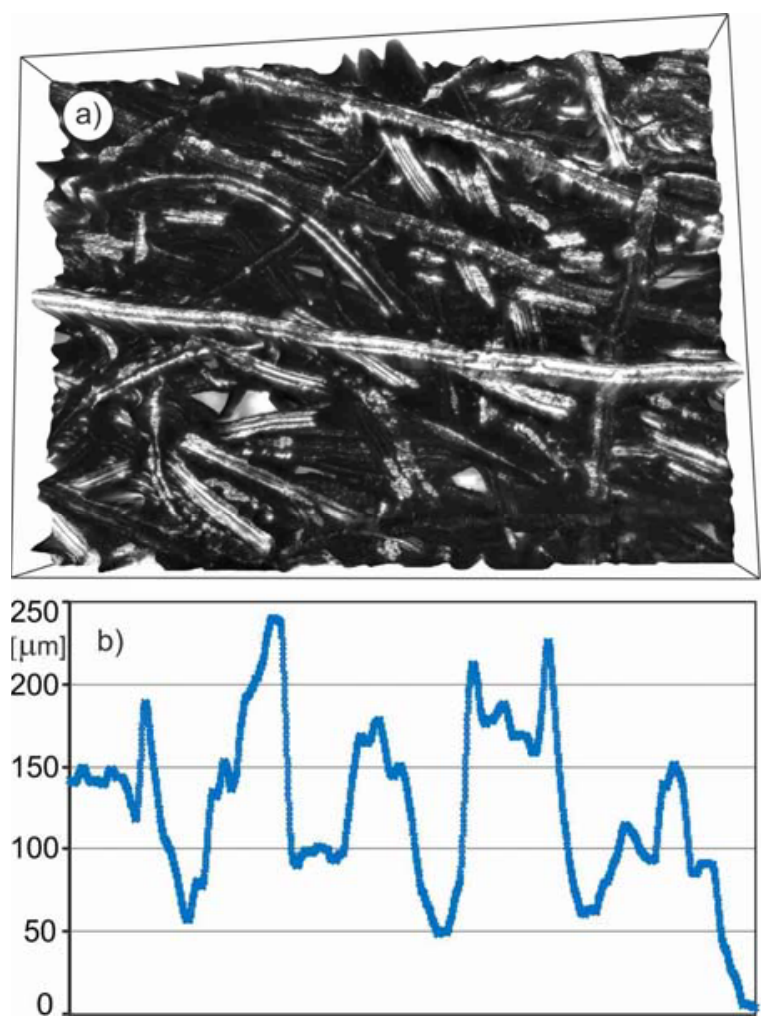

Fig. 6. Porous surface produced by soldering stainless steel fibres, type 2 (average fibre diameter - $25 \mu \mathrm{m}$ ): a) $3 \mathrm{D}$ topography, $\mathrm{b}$ ) roughness profile.

\subsection{Experimental stand}

The test stand facility was based on the literature review. In the process of the test stand constructing it was needed to eliminate its structural defects and to reduce material which were used in previous design.

Figure 2 shows the schema of the experimental stand. It consists of the following modules:

- the base module;

- the heating unit (along with the measurement of electrical power supply);

- the module of temperature measurement;

- the power measurement and control of supplied electric power module

- water supply, the cooling and condensate recovery system.

The base module consists of: an electric heater with a power of $1100 \mathrm{~W}$, a copper core responsible for the accumulation and transport of heat between the heater and a sample and a copper disc (on which a sample of the porous structure is placed). In the core holes for thermocouples were drilled and grooves were incised under the spacer. In these grooves thermocouples were placed, located in the axis of the test sample. The base module are placed in thermal insulation made from carbon-fibre. 


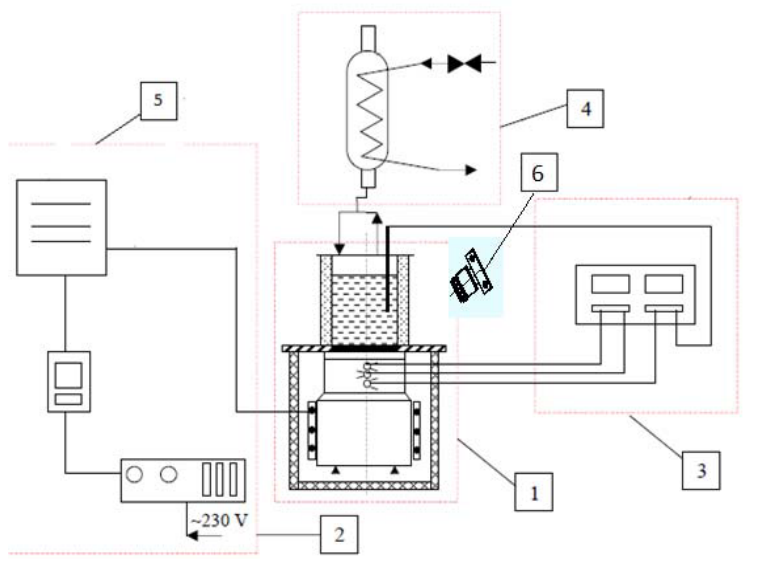

Fig. 6. Diagram of the experimental test of pool boiling heat transfer-[10] 1-base module; 2-heating unit; 3-the module of temperature measurement; 4-water supply, the cooling and condensate recovery system; 5 -the power measurement and control of supplied electric power module; 6-the visualization of boiling.

\subsection{Experimental procedure}

Study on pool boiling on porous surfaces was carried out for water at atmospheric pressure. The test procedure has to precede the boiling heat transfer investigation in which the technically smooth surface made of stainless steel was used. On the basis of the test results boiling curves were constructed. Then, the experimental procedure of research on pool boiling heat transfer intensification is carried out and several microstructured surfaces of different structural parameters were tested.

After the test procedure, the intensive boiling is provided, once the fluid is degassed and fluid temperature achieved the saturation temperature. Then the process is carried out slowly, while the heat flux supplied to the sample are increased due to a power supply and a resistive heater placed on a copper cylinder. Gradually increasing of the heat flux in long intervals in the stationary state is conducted to stabilize the thermal condition in the sample. This is possible because a high thermal capacity of the heater (a heating roller), to which the sample is soldered. The heat flux is calculated from the electric power supplied to the heater and the comparative temperature distribution in the copper cylinder. Electric power during measurements is reduced by the heat losses to the environment, determined from the heat balance for the whole experimental stand. It allows to specify the amount of supplied heat flux. Figure 3 shows the position of the thermocouples in the heating roller. Such an arrangement of thermocouples allows to determine the temperature at the surface of the sample by extrapolation of the temperature distribution.

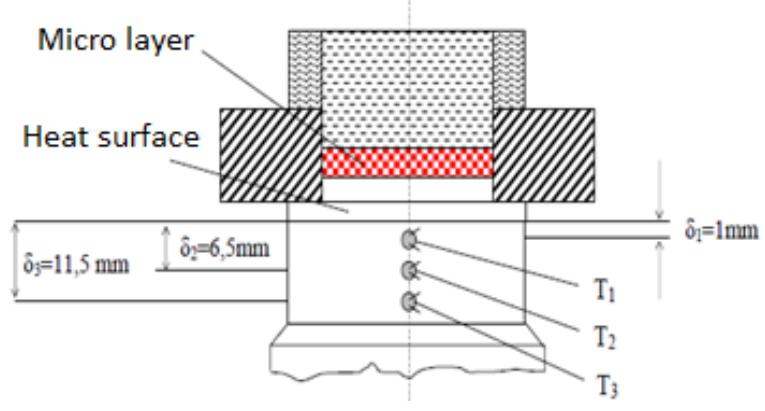

Fig. 8. The scheme of thermocouples arrangement in the basic module.

\section{The results of experimental studies}

Results are presented as boiling curves i.e. heat flux $q$ versus surface superheating $\Delta T$, with heat flux increasing, similarly as in Fig. 1. Results of experimental tests conducted using a technical smooth surface $(\mathrm{Ra}=5)$ are shown in Fig. 9.

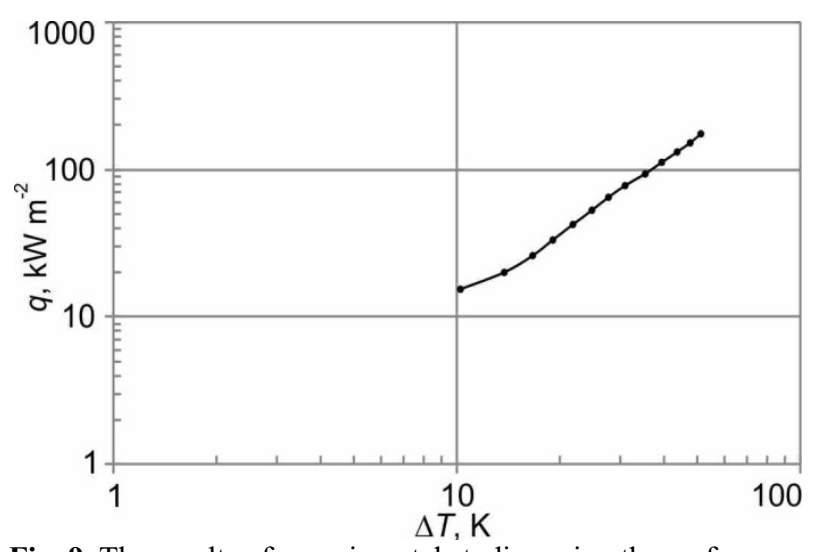

Fig. 9. The results of experimental studies using the surface made of stainless steel, technically smooth.

Test results of experiments carried out using the above-described modified surfaces were compared with the results for the sample of technically smooth surface, in order to illustrate the impact of the application of the developed surfaces, Figs. 10-14.

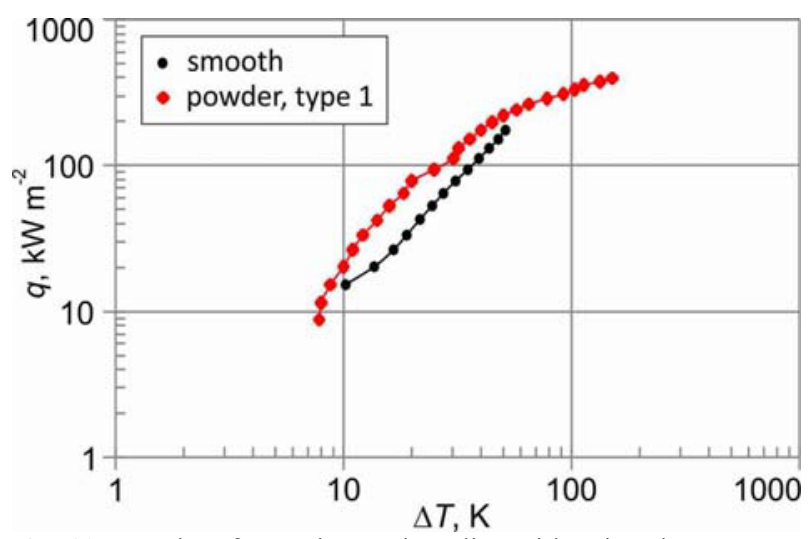

Fig. 10. Results of experimental studies with using the porous surface produced by sintering iron powder, type 1 . 


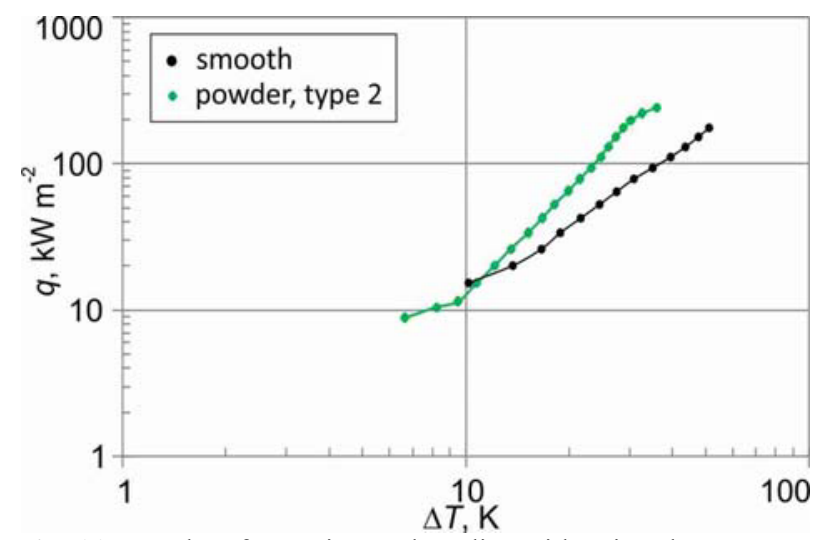

Fig. 11. Results of experimental studies with using the porous surface produced by soldering iron powder, type 2 .

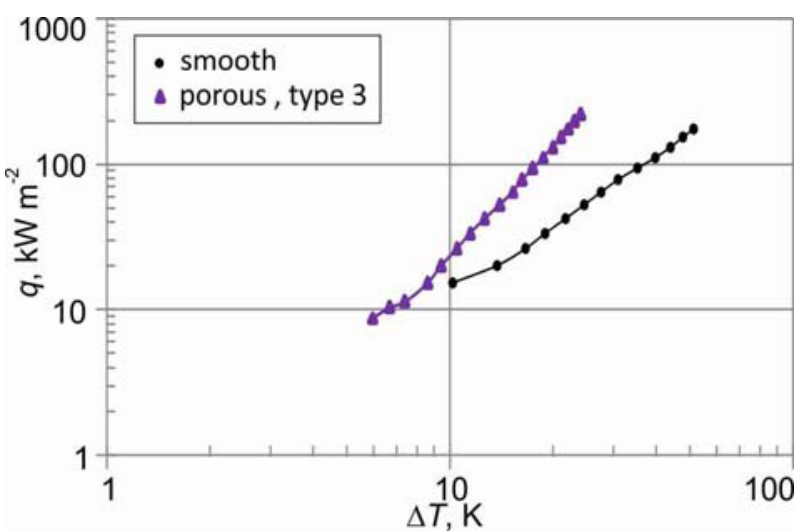

Fig. 12. Results of experimental studies with using the porous surface produced by soldering iron powder, type 3 .

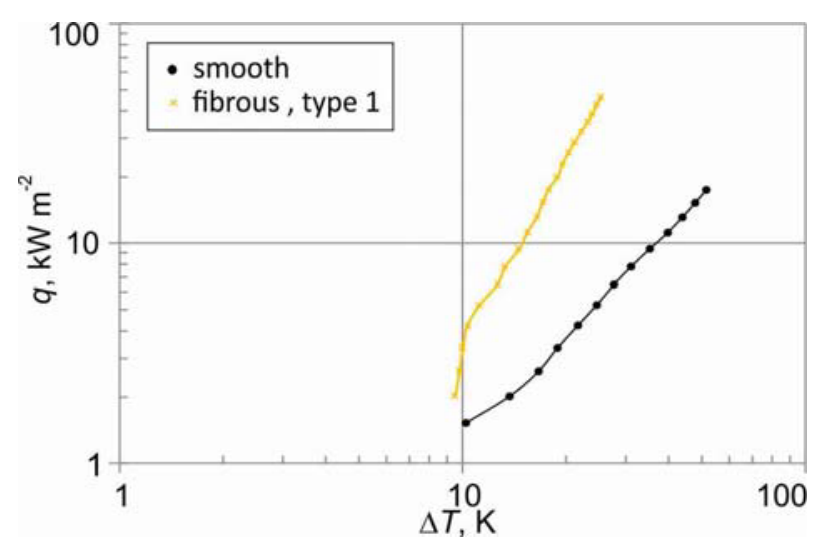

Fig. 13. Results of experimental studies with using the surface enhanced by soldering stainless steel fibres, type 1 .

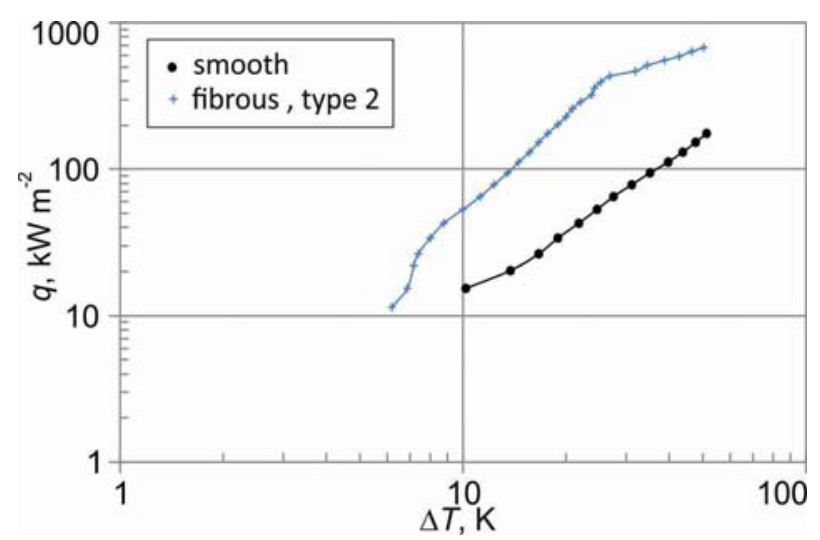

Fig. 14. Results of experimental studies with using the surface enhanced by soldering stainless steel fibres, type 2 .

\section{Analysis of the results}

Table 1 shows a comparison of the values of the heat transfer coefficients obtained for modified surfaces-with the technically smooth one, for the constant surface superheating of $10 \mathrm{~K}$.

Table 1. Heat transfer coefficient and heat flux for the constant surface superheating of $10 \mathrm{~K}$, results from experiments with using different heated surfaces.

\begin{tabular}{|c|c|c|c|}
\hline Sample name & $\boldsymbol{\Delta T}$ & $\boldsymbol{q}$ & $\boldsymbol{\alpha}$ \\
\hline- & $\mathrm{K}$ & $\mathrm{W} \cdot \mathrm{m}^{-2}$ & $\mathrm{~W} \cdot \mathrm{m}^{-2} \cdot \mathrm{K}^{-1}$ \\
\hline smooth surface & 10 & 15282 & 1498 \\
\hline powder type 1 & 10 & 20163 & 2016 \\
\hline powder type 2 & 10 & 12882 & 1288 \\
\hline powder type3 & 10 & 23374 & 2337 \\
\hline fibrous type 1 & 10 & 20197 & 2019 \\
\hline fibrous type 2 & 10 & 52717 & 5271 \\
\hline
\end{tabular}

Figure 15 presents the heat transfer coefficient versus the heat flux obtained for boiling of water at atmospheric pressure obtained from experiments with using different heated surfaces.

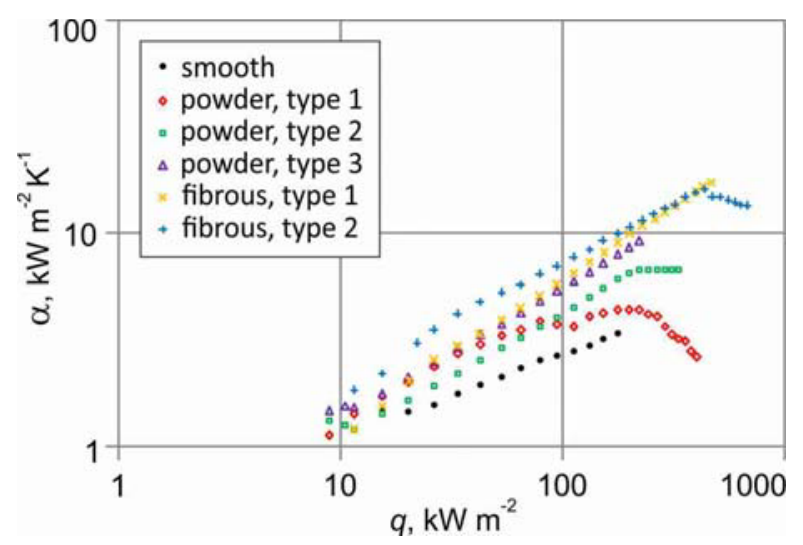

Fig. 15. Heat transfer coefficient versus the heat flux obtained for boiling of water at atmospheric pressure from experiments with using different heated surfaces.

Analysis of results has shown that all applied coatings on the heated surface causes heat transfer intensification in comparison to obtained for the smooth surface. In case of using the surfaces enhanced by soldering fibres in experiments, increasing diameters of fibres results in increasing values of the heat transfer coefficient at lower heat flux. At the same time, diminishing of the heat transfer coefficient is observed for this surface at higher heat flux, close to the critical heat flux.

It was also observed that when size of the powder granulate in the porous surface is larger, the higher values of the heat transfer coefficient are obtained. However, at higher heat flux, increasing the thickness of the porous powder layer significantly deteriorates the heat transfer. 


\section{Conclusion}

With the rapid development of electronic, nuclear, space, military, medical and other technologies, accommodation of very high heat fluxes have become one of the most heavyweight problems to solve. A growing amount of heat emitted by large capacity computer processors creates a demand for more intensive cooling techniques. Heat transfer on smooth surfaces, even via boiling, is becoming insufficient and creates an urgent need for new solutions.

For more than twenty years, the authors have been conducting thorough theoretical and experimental studies of pool boiling heat transfer enhancement on extended surfaces, with the focus on developing new technologies, producing new structures on a lab scale, and application problems including the heat transfer regulation via boiling.

Results from the study have shown that the highest intensification of pool boiling heat transfer was achieved in experiments with using the porous surface enhanced by soldering stainless steel fibres, type 1 . The heat transfer coefficient reached more than $500 \%$ of the value obtained for the smooth surface.

\section{Acknowledgments}

The research has been financially supported by the National Scientific Center from funds granted by virtue of decision No. DEC-2013/09/B/ST8/02825.

\section{References}

1. M. Piasecka, Ann. Nucl. Energy 73, 282-293 (2014)

2. M. Piasecka, Int. J. Refrig. 56, 198-212 (2015)

3. M. Piasecka, Int. J. Heat Mass Transf. 81, 114-121 (2015)

4. M. Piasecka, K. Strąk, B. Maciejewska, Heat Transf. Eng. 38 (3) (2017), DOI: 10.1080/01457632.2016.118927, (in print)

5. R. Pastuszko, M. Piasecka, Journal of Physics: Conf. Ser. 395, 012137 (2012)

6. W. Depczyński, R. Kazała, K. Ludwinek, K. Jedynak, Materials 9 (7), 567, 1-12 (2016)

7. W. Depczyński, Proc. 23rd Int. Conf. Metallurgy Materials METAL 2014, Poland (2014)

8. M. Piasecka, the Polish patent application A method for porous structures producing on the surface of metal products, No. A1 415204 (2015) (in Polish)

9. T.M. Wójcik, W. Kalawa, M Balice, Energy and Fuels in XXI century, 189-198 (2014) (in Polish)

10. T.M Wójcik, Boiling incipience and hysteresis of heat transfer on porous coatings, Series Hearing, Monographs 204 (the Publishing House of the AGH Univ. of Sc. and Techn. 2010) (in Polish) 